\title{
Reflexiones sobre el alcance de las teorías médicas ilustradas. El ejemplo de Félix Ibáñez, tratadista epidemiológico y médico de Pastrana
}

(Alcarria)

Considerations about Medical Theories Illustrated. Félix Ibáñez, a Epidemic Researcher and Doctor of the Town of Pastrana (Alcarria, Sapin)

Esther Alegre Carvajal

UNED

CESXVIII, núm. 30 (2020), págs. 13-35 DOI: https://doi.org/10.17811/cesxviii.30.2020.13-35

ISSN: 1131-9879

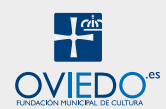




\section{RESUMEN}

Félix Ibáñez médico titular de la villa de Pastrana, formó parte del específico conjunto de médicos que, en la España de la segunda mitad del siglo XVIII, tuvieron una formación en las nuevas teorías de la Medicina científica. Él es un ejemplo temprano de esa literatura médica que se ocupó de forma empírica del problema epidemiológico. Con gran capacidad investigadora y de observación, una profunda erudición y un conocimiento preciso de todas las teorías modernas sobre enfermedades contagiosas escribe su Topografía Hipocrática (1795) en la que analiza la grave epidemia de Tercianas que azotó a la Alcarria desde 1784 y hasta 1791. El objeto de este artículo es analizar la figura de este singular médico, su formación, el contexto en el que se gesta su obra, el propio desarrollo de la epidemia y finalmente la repercusión de su conocimiento y su práctica médica.

Palabras clave

Tercianas; Epidemiológia; Pastrana; Félix Ibáñez; Conde de Cabarrus; Historia de la Mecina.

\section{AbSTRACT}

Félix Ibáñez, doctor of the town of Pastrana, was part of doctors who, in Spain in the second half of the 18th century, had a medical background from clear scientific postulates. Thanks to it, developed a research and observation capacity that is reflected in a medical literature that empirically addressed the epidemiological problem. Félix Ibáñez wrote a Hippocratic Topography (1795), in which he researches epidemic "Tercianas" that affected thousands of people in Alcarria (Spain) from 1784 till 1791. His work explains a deep knowledge about all the modern researches about contagious illnesses, and the most innovative treatments. The purpose of this paper is to analyze the singular doctor, Félix Ibáñez, his training, the context in which his work is brewed, the development of the epidemic itself and finally the impact of his knowledge and medical practice.

Key Words

Medical Literature; Pandemic; Epidemiological Studies; Pastrana; Félix Ibáñez; Alcarria.

Recibido: 16 de enero de 2020. Aceptado: 10 de marzo de 2020. 
En 1795 vio la luz en Madrid, en la imprenta de Ramón Ruiz, la obra titulada Topografía Hipocrática, ó descripción de la epidemia de calenturas intermitentes, tercianas malignas, continuo-remitentes, perniciosas complicadas, que se han padecido en la provincia de la Alcarria desde el año 1784 hasta 1790 y 1791, escrita por Félix Ibáñez ${ }^{1}$ (ca. 1738-1808), médico ilustrado, que ejerció como tal, una gran parte de su vida en Pastrana, localidad situada en la Alcarria territorio al que dedica su análisis.

Este estudio y su particular autor, resultan altamente interesantes puesto que el médico llamado exclusivamente Félix Ibáñez ${ }^{2}$, formó parte del restringido conjunto de facultativos tratadistas que, en la España del siglo XVIII, tuvieron acceso a la medicina científica y se ocuparon de forma empírica del tema epidemiológico. Su obra, fue una de las primeras en impulsar el género de las Topografías ${ }^{3}$ - literatura médica de enorme desarrollo posterior- y pone de manifiesto los estrechos contactos con la medicina europea tanto en la formación como en el trabajo de su autor. En ella Félix Ibáñez, analiza y narra pormenorizadamente la grave epidemia de Tercianas ${ }^{4}$ que asoló la Alcarria en la década de 1780, y que él atendió en su calidad de médico titular de Pastrana. Siguiendo el espíritu empirista de los científicos ilustrados, su obra incluye un gran número de historias clínicas y muchas reflexiones sobre este terrible episodio epidémico.

1 Félix IBáñEz, Topografía Hipocrática, ó descripción de la epidemia de calenturas intermitentes, tercianas malignas, continuo-remitentes, perniciosas complicadas, que se han padecido en la provincia de la Alcarria desde el año 1784 hasta 1790 y 1791. Madrid, Imprenta de Ramón Ruiz, 1795.

2 Sobre Félix Ibáñez: Juan Riera Palmero, Fiebres y paludismo en la España Ilustrada (Félix Ibáñez y la epidemia de La Alcarria, 1784-1792), Valladolid, Universidad de Valladolid, 1984. Esther Alegre CARVAJAL, «El discurso médico-higienista ilustrado y su incidencia en Pastrana, una ciudad ducal del Renacimiento», en Urquizar y Sazatornil (eds.) Arte, ciudad y culturas nobiliarias (siglo XV al XVIII), Madrid, CSIC, 2019, págs. 250-263.

3 El médico asturiano Gaspar Casal y Julián (1680-1759), es considerado como el iniciador de este género en España con su obra: Gaspar Casal, Historia Natural y Médica de Asturias, Madrid, 1762. Edición de la Diputación de Oviedo, 1959. Sobre Topografías médicas y su desarrollo ver: Luis URTEAGa GonZÁLEZ, «Miseria, Miasmas y Microbios. Las Topografías Médicas y el estudio del medio ambiente en el siglo XIX», en Cuadernos Críticos de Geografía Humana, 29 (1980); Juan Casco Solís, «Las Topografías Médicas: revisión y cronología», en Asclepio, vol. LIII-1 (2001), págs. 213-244.

4 Terciana es el término con que se conocía en la época la malaria o paludismo. Se trataba de una fiebre intermitente que se repite cada tres días. 
Sobre Félix Ibáñez se pueden juntar escasos datos biográficos, aunque suficientemente significativos. Sabemos que nació en 1738 o 1739, gracias a su propia historia médica, escrita en 1790 o 1791, donde apunta «soy hombre de naturaleza sanguineobiliosa, edad de cincuenta y dos años» ${ }^{5}$. Era natural de Madridejos (Toledo) y estudió en la universidad de Alcalá de Henares ${ }^{6}$. Terminada su formación académica, es muy probable que viajara por Europa, dentro de la costumbre del Gran Tour, ya que muestra un preciso conocimiento de los avances médicos europeos y una alta erudición en cuanto a las modernas teorías sobre epidemiología. Al tiempo manifiesta su frustración y aboga por instituciones médicas donde realizar un aprendizaje más correcto y experimental de la medicina.

En 1764, con 25 años, da comienzo su ejercicio profesional primero en Huete y posteriormente en Pastrana ${ }^{7}$, donde permanece hasta el final de su vida. En Huete contrajo matrimonio con Bernarda Romo y Corona y nacieron sus tres hijos, Mariano (1766), Ramona (1765) y Francisca (1773). A Pastrana llega en $1780^{\circ}$, a la edad de 41 o 42 años, es un hombre de mediana edad y un experimentado e inquieto médico que desea progresar. Su nuevo destino, esta vez como médico titular, supuso un importante ascenso en su carrera profesional ${ }^{9} \mathrm{y}$ tenemos noticias de su actividad para consolidar tanto su posición económica como social ${ }^{10}$. Aunque es indudable que el momento álgido de su actividad, se produce durante los largos siete años que persiste la grave epidemia de Tercianas que asoló la Alcarria entre 1784 y 1791.

Su historia familiar, la conocemos gracias a su Topografía, donde narra las historias clínicas de cada uno de los miembros de la familia Ibáñez, todos se

5 Iвáñ̃z, Topografía, pág. 165.

6 Archivo Histórico Nacional (en adelante AHN) Universidades, 470, exp. 8.

7 Huete pertenece, actualmente, a la provincia de Cuenca y Pastrana a la de Guadalajara, pero en el momento de la vida de Félix Ibáñez, ambas poblaciones formaban parte de la comarca de la Alcarria.

8 Archivo Municipal de Pastrana (en adelante AMP), 34.9. s/f, "Carta de Félix Ibáñez dirigida al Ayuntamiento, 5 de febrero de 1798» donde expone: «Que desde el año de 1780 está sirviendo a este vecindario".

9 La figura de «médico titular» aparece en el siglo XVIII, se trata de un profesional que trabaja de forma exclusiva para un núcleo de población. El acceso a una plaza médica vacante se realizaba por concurso libre. En el caso de Pastrana conocemos bien su procedimiento por la renovación del contrato de Félix Ibáñez que se realiza en 1796, Archivo Histórico Provincial de Guadalajara (en adelante AHPG), sig. 5619.

10 En 1784 tuvo problemas de dinero: AMP, sig. 34.9. s/f, «Carta de Félix Ibáñez dirigida al Ayuntamiento, 5 de febrero de 1798». Y en 1785 por esta razón interpuso un pleito al Concejo de Pastrana porque no había cobrado lo acordado: Archivo de la Real Chancillería de Valladolid (en adelante ARCHV). Consejos, 27258, Exp. 39. «El doctor Félix Ibáñez, médico titular de la villa de Pastrana (Guadalajara), sobre que por las justicias de dicha villa se repartan 100 ducados que le pertenecen de aumento de su sueldo». 
vieron afectados sucesivamente por la epidemia. En primer lugar en 1787 enfermó su hija Ramona, de 22 años, casada en la localidad de Peñalver, próxima a Pastrana, y se curón ${ }^{11}$ En noviembre de 1788, él mismo se puso enfermo, lo que no le impide incluir su propia historia clínica. Un año después, el 15 de marzo de 1789, su esposa también enferma y fallece por tercianas, a la edad de 49 años. Su historia clínica, aunque pretende no abandonar el tono objetivo y científico propio del conjunto de la obra, es mucho más detallada que otras historias e introduce reflexiones personales cómo: «Nada bastó y todo fue en vano, pues en cumpliéndose el plazo y término último, no hay Médico ni medicina que falsifiquen el statutum de San Pablo, y así aguanté toda la noche hasta el ocho que feneció.... ${ }^{12}$.

Un año después, el 7 de noviembre de 1791, también cayó enferma su hija pequeña, Francisca, con 18 años: «sana, fuerte, robusta, gruesa y encarnada $[\ldots]$ y aunque estuvo apique de perder la vida [...] quedó libre de calentura, la convalecencia fue pronta y prospera» ${ }^{13}$. Y apenas un mes después, el 23 de diciembre del mismo año, fallece su hijo Mariano. En esta ocasión, dominado por la pena, ni siquiera puede ofrecer una narración precisa del transcurso la enfermedad:

Habiendo salido de esta villa el bachiller don Mariano Ibáñez, mi muy amado hijo, para la villa de Peñalver con el destino de acompañar en el camino a su hermana Ramona, permitió Dios que se sintiese malo este joven, de edad de veinte y cinco años, en que estava (sic) rebosando de salud y robustez de esta indisposición fue asaltado y en catorce días de calentura contagioso maligna fallecióo ${ }^{14}$.

Tras el episodio de Tercianas, su profesionalidad se ve reconocida con la renovación de su contrato cómo médico titular en 1796 donde se acuerdan altos emolumentos y períodos vacacionales ${ }^{15}$, y en 1798 , cuando solicita usar un $\mathrm{Pa}$ sante (médico auxiliar) «por la consecuencia de muchos vecinos y serle a uno solo insoportable el trabajo», y nuevamente revisar su salario, puesto que gozaba de una ventajosa propuesta: «habiendo sido electo para medico titular de

11 Iвáñez, Topografía, Suceso I, págs. 192-193.

12 IвáñEz, Topografía, págs. 173-179.

13 Iвáñez, Topografía, pág. 180.

14 IвÁÑ̃E, Topografía, pág. 202.

15 AHPG, sig. 5619 «Escritura de obligación a favor del Dr. Don Félix Ibáñez, médico titular de esta Villa»: «Es condición se le han de conceder y conceden en cada uno de los dichos ocho años al mismo médico veinte días de descanso o recles con cuyo motivo y no otro ha de poder ausentarse de esta villa no habiendo enfermos de cuidado pero habiéndolos lo suspenderá hasta el restablecimiento y precediendo antes la licencia correspondiente». 
la villa de Chinchón con el salario de 12800 reales y otros emolumentos que en todo componen quince mil reales lo pone como es justo y valido en conocimiento de VS, para que sirva deliberar sobre el asunto ${ }^{16}$. Estos ajustes le permitieron disfrutar de un considerable desahogo económico y asegurar su futuro ${ }^{17}$.

Más interesante es la última petición que dirige al Ayuntamiento de Pastrana en 1802, en la que solicita una pensión para poder retirarse y un insólito privilegio: «que por los méritos que ha contraído en ella con su vecindario se aprueben los acuerdos del Ayuntamiento, concediéndole asiento en el Banco de nobles de la Yglesia Colegiata» ${ }^{18}$. Ocupar el «banco de nobles» presuponía una categoría, cuando menos, pre-nobiliaria, y por lo tanto un alto reconocimiento social. Félix Ibáñez sigue de cerca el ejemplo del afamado médico Joseph Masdevall, epidemiólogo como él y más o menos de su misma edad que, tras ser nombrado médico de Cámara de su Majestad, por tanto considerado entre los más cultos y preparados, fue ennoblecido ${ }^{19}$. Elocuentemente, Félix Ibáñez narra en su Topografía esta consideración: «Joseph Masdevall por conseguir eliminar la epidemia de tercianas en el principado de Cataluña. En el año 1787, recibió el título de Caballero por parte del rey Carlos III ${ }^{20}$, creando una sorprendente equivalencia que debía ser confirmada con ese «asiento en el Banco de nobles de la Yglesia Colegiata».

Esta larga y exitosa carrera profesional estuvo acompañada de una importante y prometedora labor de investigación y difusión científica que, sin embargo, fue interrumpida bruscamente a partir de 1791 y simplemente avanza para lograr la publicación de su Topografía en Madrid. Es inevitable pensar que la muerte de su esposa, en primer lugar, y mucho más la de su hijo, produjeron en él un hondo pesar y un franco desengaño con la práctica de la medicina, disipando su entusiasmo hacia los nuevos métodos científicos ${ }^{21}$ y su vocación de investigación epidemiológica.

16 AMP, sig. 34.9. s/f, «Carta de Félix Ibáñez dirigida al Ayuntamiento, 5 de febrero de 1798».

17 Félix Ibáñez se convierte en importante propietario de tierras a través de compras y permutas en 1799: AHPG, sig. 5619 «Ventas a favor de Don Félix Ibáñez» y «Escritura de cambio entre Don Félix Ibáñez y Nicolás Martínez».

18 AMP, sig. 35.4, s/f, 31/05/1802.

19 José Luis Bertrán Moya, Historia de las epidemias en España y sus colonias (1348-1919), Madrid, La esfera de los libros, 2006, pág. 108, asegura que «Sin duda ejemplo de la simbiosis que se está tejiendo entre medicina y política en el siglo XVIII».

20 IвÁñez, Topografía, Discurso Preliminar X.

21 Tal vez podemos ver la influencia de, médico de la Universidad de Valencia, que sufrió una crisis de confianza en la medicina, tal y como se la concebía hasta entonces, provocada por la muerte de su esposa en 1750 . 


\section{Formación académica}

En esa segunda mitad del siglo XVIII, entre los profesionales de la medicina existía una preocupación profunda sobre la calidad de la formación académica que se dispensaba en las universidades españolas, aunque a lo largo de toda la centuria, el reformismo fue continuo ${ }^{22}$, y poco a poco las universidades fueron renovando sus planes de estudio, modernizándolos y equiparándolos con las más modernas universidades europeas. Una de ellas fue la universidad de Alcalá de Henares, donde cursó sus estudios Félix Ibáñez ${ }^{23}$, una excepción que empezaba a no resultar tan extraña.

En este sentido es muy interesante el paralelismo que se puede establecer entre Félix Ibáñez y su colega el facultativo Vicente Crespo médico de Brihuega (Alcarria) — población muy próxima a Pastrana-, que escribe un largo e interesante Memorial (1785), dirigido al Conde de Floridablanca ${ }^{24}$. Vicente Crespo había cursado sus estudios en la universidad de Valencia, una institución modernizada y reputada, con profesores-médicos tan afamados como Andrés Piquer Arrufat (1711-1772) catedrático de anatomía, pionero en la disección y la indagación microscópica, cuyas enseñanzas eran bien conocidas por los dos facultativos de la Alcarria, que aluden a él continuamente como un principio de autoridad.

Por tanto, Félix Ibáñez y Vicente Crespo, pese a sus continuas críticas sobre la pésima situación de la enseñanza médica en España, formaron parte de un 'restringido' grupo de médicos que tuvieron acceso a un conocimiento científico de la Medicina en ese siglo XVIII. Ambos profesionales nos permiten pensar que el reformismo-medico ilustrado era capaz de llegar más allá de las capitales de provincia, para incrustarse en las villas, núcleos intermedios del territorio del Estado que como Pastrana o Brihuega, en la Alcarria, eran vertebradoras de pueblos y aldeas menores ${ }^{25}$, y permiten que nos cuestionemos la 'limitación y excepcionalidad' de ese grupo de médicos-científicos, al menos como paradoja.

22 En 1734 se crea la Real Academia Médica Matritense; a mediados de siglo aparecen Colegios de Cirugía en Cádiz, Barcelona y Madrid. Estas instituciones tendrán una influencia decisiva en la reforma de la enseñanza y la práctica médica, así como en la investigación científica.

23 La Universidad de Alcalá reformó el plan de estudios médicos en 1771, cuando el Plan de la Facultad de Medicina de la universidad de Salamanca, aprobado en 1766, fue ratificado gubernativamente y se generalizó para el resto de las universidades.

24 Mikel Astrain Gallart, «La práctica médica en el medio rural castellano. El Memorial de Vicente Crespo (1785)», Dynamis, 22, 2002, págs. 461-472. El documento: Archivo General de Simancas (en adelante AGS), Gracia y Justicia, leg. 990. 30/12/1784.

25 En la nueva estructura del estado del siglo xIX pasaron a ser lo que se denominó 'cabezas de partido'. 
Pero sus categóricas afirmaciones nos permiten, al mismo tiempo, observar las graves contradicciones en las que se debatía todavía la Medicina. Vicente Crespo está convencido de que la «deplorable» formación de los médicos es el principal mal de la práctica médica e impide ejercer lo que él denomina la «verdadera medicina» ${ }^{26}$. Por su parte Félix Ibáñez explica que todavía la medicina era ejercida por los «Anti-médicos»: grupos de sanadores, cirujanos, barberos, boticarios, sangradores, curanderos, sin una formación suficiente e institucionalizada, a los que considera: «irreconciliables enemigos de la salud pública del linaje humano» ${ }^{27}$. Y frente a ellos defiende: «apesar de los obstáculos que ofrece la barbarie del vulgo y la mordacidad de los Anti-Médicos, me he empeñado en sostener y defender la salud y vida de todos, que es el principal designio de mi profesión ${ }^{28}$, y más adelante apunta: «Yo mismo, en diferentes ocasiones he sido insultado por semejantes calumniadores» ${ }^{29}$. Este mismo problema es apuntado por Vicente Crespo: «son más perniciosos a la república que una cuadrilla de famosos bandoleros ya que no solo matan y roban, sino que además persiguen al médico» ${ }^{30}$. Pero de forma paradójica, esa medicina no científica, mantiene aliados, como el propio Benito Feijoo quien pese a defender una medicina experimental, no desprecia el saber popular cuando éste demostraba su utilidad ${ }^{31}$. Lo que nos revela la obligatoria necesidad de establecer los límites de la profesión.

\section{Obra escrita e investigación}

Para Félix Ibáñez, su práctica médica va a estar íntimamente relacionada con el conocimiento de las novedades científicas más recientes, como tendremos ocasión de comprobar. Novedades que conoce detalladamente y adquiere

26 Astrain Gallart, «La práctica médica... pág. 464.

27 Iви́ÑEz, Topografía, Discurso Preliminar V. Pocas líneas más adelante añade: «Entre los mismos facultativos hay ciertos Anti-Médicos mucho más criminales que la caterva y muchedumbre de Sabios aparentes».

28 IвÁñEz, Topografía, Dedicatoria inicial.

29 IBÁÑEz, Topografía, Discurso Preliminar X.

30 Tanto un médico como el otro atacan a los facultativos «clásicos», declarándose ambos partidarios de la renovación de los estudios de medicina, cosa que como se ha apuntado estaba ocurriendo a lo largo de la centuria.

31 Benito Jerónimo Fejoo, Teatro crítico universal, o Discursos varios en todo género de materias para desengaño de errores comunes. Tomo I. La primera edición de este Tomo I es de 1726 [http://www.cervantesvirtual.com/obra/teatro-critico-universal--0/] [Madrid, Imprenta de Blas Román, 1778. http://www.filosofia.org/ bjf/bjft105.htm; Consulta: 07/08/2019]. La influencia intelectual de B. Feijoo a lo largo de toda la centuria del ochocientos fue inmensa, por tanto su crítica exacerbada a la situación de la Medicina, y sobre todo sus dudas sobre la incipiente medicina científica o experimental, crean la impresión de inconsistencia e impiden una clara confianza en los médicos y la medicina. 
con avidez y rapidez, gracias al gran impulso de las publicaciones médicas ${ }^{32}$. Indudablemente poseyó una copiosa biblioteca especializada. En su Topografía hace alusiones con referencias muy precisas a un amplísimo conjunto de obras que solo podría citar manejándolas directamente, es decir, a través de su posesión personal. Un ejemplo de ello serían las obras del ya mencionado doctor Andrés Piquer Arrufat.

$\mathrm{Su}$ vocación como investigador y estudioso de la enfermedad cristaliza no solo en la ya mencionada Topografía (1791), sino también en otra serie de estudios que no llegaron a la imprenta. Por una parte, demostrando su alta erudición, tradujo al castellano la obra latina del médico italiano Burserio y Kanifeld [Burserius De Kanifeld], Institutionum Medicina e practica quas auctoribus suis pralegebat, que se publicó en Milán entre 1781 y 1788 en cuatro volúmenes, los dos últimos tras la muerte del autor ${ }^{33}$. Félix Ibáñez indudablemente utilizo una de las primeras ediciones italianas — lo que nos afirma en que se mantenía al corriente de las novedades editoriales y que eran rápidamente adquiridaspuesto que ya había realizado su traducción en 1790 cuando escribe en su Topografía: «Y para mejor inteligencia de todos le tengo traducido del latín al castellano, y juzgo sería muy importante que diese a la imprenta esta traducción por ser obra de los mejores que sustentan nuestros estantes médicos» ${ }^{34}$. Podemos pensar que realizó la traducción como una forma de estudio personal puesto que coincide con los años de virulencia de la epidemia de Tercianas (1784-1791). Finalmente, su trabajo no se publicó porque se interpuso la edición del médico escocés Willian Cullen (1710-1790) titulada Elementos de Medicina Práctica ${ }^{35}$, una edición anotada y comentada sobre la obra de Burserius De Kanifeld que tuvo un gran éxito y que rápidamente fue traducida al francés por Bosquillon ${ }^{36}$

32 Luis S. Granjel, El libro médico en España (1808-1936), Salamanca, Universidad. Instituto de Historia de la Medicina Española, 1975. Aunque inicia el recuento de publicaciones unos años más tarde que nuestro relato, podemos hacernos una idea muy aproximada de la importancia de las publicaciones médicas España, donde entre 1808 y 1936 se publicaron 487 libros de higiene, de los cuales 434 eran de autores españoles; a los que hay que añadir otros 331 específicos sobre epidemias.

33 Joannis Baptitae Burserii De-Kanifeld (1725-1785), era un médico italiano, nacido en Trento de gran fama. Su obra Institutionum Medicina... deriva de la creencia de que se podía una teoría general de la enfermedad humana que lo integrara todo y por tanto era posible integrar todo el saber de forma enciclopédica en una obra. Información sobre el autor en: Jean Baptiste GLaIRE (dir), Enciclopédie Catholique, répertoire universal et raisonne des Sciences, des Lettres, des Arts et des Métiers, París, tomo IV, 1842, pág. 99; y M. MichauD (dir), Biographie Universelle, ancienne et moderne, París, tomo V, 1843, pág. 104, voz: Borsieri de Kanifeld.

34 Iвáñez, Topografía, Discurso Preliminar XVII. La alusión a los «estantes médicos» es una metáfora que nos habla de su biblioteca personal y de la gran difusión de la literatura médica.

35 José L. Fresquet Febrer, «William Cullen (1710-1790)», Historia de la Medicina, Marzo (2014). Disponible en: http:// http://www.historiadelamedicina.org/cullen.html [Consulta: 5/04/2018].

36 Édouard-François-Marie Bosquillon (1744-1814) médico francés. Tradujo la obra de William Cullen, con el título Éléments de médecine pratique, 2 volS., 1785-1787. 
y al castellano en 1788 por Bartolomé Piñera y Siles ${ }^{37}$, médico de Cámara. Esta obra gracias a una Real Orden se convirtió en texto obligatorio de estudio en todas las universidades y Colegios médicos del reino ${ }^{38}$.

Si fue llevada a la imprenta en 1795, su Topografía Hipocrática, donde recoge la incidencia de la epidemia de Tercianas que asoló la Alcarria desde 1784 hasta 1791. Y es a través de esta obra como conocemos otros interesantes proyectos de Félix Ibáñez, que permanecieron inacabados como la Suma Histórico Médica Crítico Práctica, que estaría en la línea de la obra de Kanifeld, y un tratado sobre la Piretología (fiebre). E incluso sobre tercianas escribió también un Diario Médico de Observaciones y una Disertación. Obras inéditas de las que solo conocemos lo que él mismo nos cuenta ${ }^{39}$. Así sobre su gran obra Suma Histórico Médica ... dice:

Si este trabajo merece entre los literatos de mi profesión la aceptación que espero, les prometo dar a la luz pública una edición interesante y necesaria a la salud de los hombres con el siguiente dictado: Suma Histórico Médica Crítico Práctica, que excluye todos los sistemas inventados desde Hipócrates hasta la época presente, é incluye y los reduce a un modo idéntico de pensar, formando un plan terapéutico general, para curar por indicaciones universales y particulares toda clase de enfermedad ${ }^{40}$.

Sus palabras y su título nos permiten pensar que se trataba de un proyecto suficientemente avanzado como para presentarlo públicamente, destinado a reunir y sistematizar los nuevos conocimientos médicos, en un intento de abandonar el simple conocimiento teórico y reforzar el conocimiento práctico; llevar el conocimiento a la práctica médica general era su objetivo. En este sentido, son muchos los tratados a lo largo del siglo XVIII que persiguen este fin, entre otros el propio William Cullen trató de establecer un sistema racionalista que explicara estos conocimientos y los uniera en un conjunto inteligible, con generalizaciones que se basaban de forma firme en la experiencia ${ }^{41}$.

37 Bartolomé Piñera Y Siles, Elementos de Medicina Práctica (por el doctor Guillermo Cullen), varios Tomos, Imprenta de Benito Cano, 1788.

38 F. J. Laso, Oracion inaugural que en sesion pública extraordinaria celebrada por la Junta Escolástica del Real Colegio de Medicina y Cirugía de Cádiz, Cádiz, Imprenta de la Viuda é hijo de Bosch, 1828. José María López Piñero, Diccionario Histórico de la Ciencia Moderna en España, Barcelona, 1983, vol.1. Luis S. Granjel, «La Medicina española del siglo XVIII», Historia General de la Medicina Española, Salamanca, 1979, págs. 174 y 195.

39 Es muy posible que tanto su Diario Médico de Observaciones y como su Disertación sobre Tercianas, e incluso su tratado sobre la Piretología, acabarán formando parte de su Topografía Hipocrática.

40 Iвáñez, Topografía, Discurso Preliminar XVII, pág. 11.

41 Fresquet Febrer, 2014. 
La noticia de su Disertación y de su Diario Médico, son muy significativas, y vuelven a traducir su interés por la experiencia práctica y por compartir y divulgar ese conocimiento. Cuando en su Topografía Hipocrática habla sobre la epidemia de tercianas que sufrió el Viso del Marqués y los pueblos aledaños en 1786, previene sobre otros síntomas y por tanto otras enfermedades asociadas, tal y como él lo había experimentado y anotado en su diario y desarrollado en su Disertación. Esta advertencia nos permite conocer que su trabajo de investigación se pone en marcha desde el momento en que se presenta la epidemia en la Alcarria, de tal forma que en 1786 ya está en condiciones de ofrecer algunas conclusiones:

Muchos y peligrosos síntomas, dignos de la mayor atención y de curarse con más presteza antes que la primera enfermedad [tercianas]. Por esta razón he tenido impulsos de dar a la Imprenta una Disertación o Noticia de que no muere el hombre por enfermedad, sino es por lo que resulta de ella. A qualquiera que quisiese leer este manuscrito se lo franquearé como lo tengo notado en mi Diario Médico de Observaciones $^{42}$.

Sobre la importancia que concede a ese Diario Médico vuelve a escribir: «formando en mi Diario Médico, un catálogo de sucesos prácticos, fundándole en repetidas observaciones prácticas, que me han servido de norma o de epacta para instituir juiciosas madureces de desengaños en el presente Proyecto o Epidemia de Tercianas» ${ }^{43}$. Y, en este sentido, desde su Introducción insiste: «puede ver el curioso las máximas cautelas que debe seguir el Médico, si leyese mi manuscrito, que dejo estampado en mi Diario de Observaciones Médicas (I)» En la Nota se lee el título del manuscrito: «Engaños de la Teoría y desengaños de la Práctica» ${ }^{44}$.

Pero indudablemente su gran obra, la que si vio la luz, y gracias a la cual tenemos conocimiento de su trabajo profesional, fue su Topografía Hipocrática (1795) que, como hemos apuntado supone un estudio sobre la grave epidemia de Tercianas que de forma general asoló España en los años 1783-86, y que intensamente azotó a la Alcarria desde 1784 y hasta 1791. Félix Ibáñez explica su incidencia en Pastrana población de la que es médico titular y, como un observador meticuloso, redacta multitud de historias clínicas individuales, entre ellas las ya mencionadas de los miembros de su familia y la suya propia.

42 IвÁñez, Topografía, Discurso Preliminar XV. El Capítulo se titula: Historia del origen variación, síntomas y manejo curativo de la Epidemia de Tercianas, I.

43 Iвáñez, Topografía, Discurso Preliminar IV.

44 Iвáñez, Topografía, Discurso Preliminar XV. 
Atiende del mismo modo a varios núcleos cercanos, Valdeconcha, Hontoba, Sayatón, Almoguera, Escopete y Yebra, donde «asistí a estos y otros pueblos de esta circunferencia en calidad de Médico de Apelación» ${ }^{45}$. Pero también aporta información sobre otras poblaciones, puesto que con sus colegas médicos mantiene una continua correspondencia «de todos tuve circunstanciadas noticias por sus peritos Médicos, y algunos de su Cirujanos ${ }^{46}$. Su obra expresa su deseo de realizar un trabajo empírico basado en la observación directa.

Las «Topografías Médicas» ${ }^{47}$ conforman una rica literatura médico-científica que vinculada a la evolución de las teorías higienistas, recoge la tradición científica según la cual la influencia del medio ambiente es básica en los procesos patológicos, y toma el espacio y el medio geográfico como objeto de estudio para explicar el origen y evolución de las enfermedades epidémicas. En este sentido las Topografías van a recoger y renovar esta tradición Hipocrática, la de Félix Ibáñez lo evidencia en el propio título de la obra Topografía Hipocrática, al prestar atención al clima y a sus variaciones como elementos para explicar las enfermedades ${ }^{48}$, doctrina que el médico griego desarrolla ampliamente en su tratado Sobre los aires, las aguas y los lugares ${ }^{49}$. El médico inglés Thomas Sydenham (1624-1689) ${ }^{50}$ había actualizado y reorganizado este conocimiento lo que permitió su amplio seguimiento en la medicina europea del siglo XVIII y dió origen a la corriente higienista que presta una singular atención al medio natural y su posible relación con los problemas patológicos.

La obra de Félix Ibáñez mantiene indudables coincidencias y similitudes con la Historia Natural del médico asturiano Gaspar Casal (1680-1759) ${ }^{51}$, el primero en intoroducir en España el modelo de observación y descripción de historias clínicas de ascendencia hipocrática. Ibáñez sigue muy de cerca el estilo de Casal en las formas y la propuesta de renovación del ejercicio de la medicina

$45 \quad$ Es decir, requerido por las autoridades municipales, para ayudar al médico titular o por enfermedad del mismo. Este es el caso «de la fiebre de que adoleció Don Antonio Calbete, Médico titular de la Villa de Yebra, de la cual falleció», IвáñEz, Topografía, pág. 157.

46 IвÁñEz, Topografía, pág. 11.

47 La importancia de esta literatura médica en: J. Luis GonZÁLEz, El Higienismo en España en el siglo XIX y el paradigma de las Topografías médicas, Tesis Doctoral, Barcelona, Universidad de Barcelona, director: Dr. Horacio Capel, 1980; Urteaga González, «Miseria, miasmas y microbios ...».

48 Sobre esta cuestión Horacio CaPEL, «Medicina y clima en la España del siglo XVIII», en 10’Revista de Geografía'; vol. XXXII-XXXIII, (1998-99), págs. 79-105.

49 Hipócrates, Tratados hipocráticos. Volumen II: Sobre los aires, aguas y lugares, Madrid, Editorial Gredos, 1997.

50 José María López Piñero, Breve Historia de la Medicina. Madrid, Alianza, 2000; José L. Fresquet Febrer, Tomás Sydenham. Historia de la Medicina, 2000. http://www.historiadelamedicina.org/sydenham. html [Consulta: 07/04/2018].

51 Gaspar CASAL, Historia Natural... 
y es un excelente precedente ilustrado del auge que alcanzaron las topografías médicas en la España decimonónica, siguiendo esta estela abierta por Casal ${ }^{52}$.

Poco después, desde fines del siglo XVIII, la formación de topografías médicas se convirtió en una tarea institucional apoyada y promovida por diversas corporaciones médicas $^{53}$, de tal forma que a principios del siglo XIX, la Real Academia de Medicina de Barcelona, encargó a uno de sus miembros más prestigiosos, el doctor Francisco Salvá, la redacción de un «plan general» al que debían ajustarse los estudios topográfico-médicos, trazándose un diseño que sirvió de marco a todos estos trabajos ${ }^{54}$; por su parte, la Real Academia Médica de Madrid, creó un concurso anual —desde 1796 — en el que otorgaba al autor de la mejor Topografía el título de «socio corresponsal». Es muy probable que la Topografía de Ibáñez fuese uno de los primeros trabajos que optara a este reconocimiento puesto que fue presentada a la Academia y fue evaluada por el doctor José Pinilla Vizcaino, como el mismo relata: «como me lo previene mi amigo el Doctor Don Joseph Pinilla y Vizcaino, Catedrático de Prima de la Universidad de Alcalá de Henares, en respuesta a la Censura que hace de este escrito» ${ }^{55}$.

Como se ha apuntado la obra muestra una profunda erudición y un vasto conocimiento sobre epidemiología, sobre las teorías más modernas de las enfermedades contagiosas y sus tratamientos ${ }^{56}$. El propio autor nos va informando a lo largo de sus páginas sobre las fuentes que construyen su estudio:

Y he formado mi proyecto a Mitación de algunos Autores de nota, y de buena práctica, sin dar otro paso que consultar las mejores Pragmaticas de Escritores, así antiguos como modernos; pero principalmente quien nos ha dirigido [...], ha sido un bello plan de calenturas intermitentes, y continuas remitentes que escribió en Latin en la Universidad de Padua el Doctor Don Juan Bautista Burserio y Kanifeld ${ }^{57}$.

52 Urteaga González, «Miseria, miasmas y microbios. ...», ofrece lo que el propio autor denomina «un primer catálogo de topografías médicas [...] Recogemos en él más de doscientos títulos, que abarcan las obras de geografía médica realizadas y publicadas entre 1800 y 1940», y afirma «Antes de 1800 se realizaron también topografías [...], pero su número, por lo que sabemos fue reducido». En este sentido Riera PaLmero, Fiebres y paludismo, pág. 46, afirma «Tanto la obra de Félix Ibáñez como la de Antonio Pérez Escobar son anteriores al desarrollo de las topografías médicas en España».

53 Luis S. Granjel, El libro médico... y Granjel, «La Medicina española... pag. 195.

54 En 1821, Francisco Salvà publica en Madrid, con otros tres socios de la Academia, Circular del plan metódico compendioso para formar la topografía de alguna población. La redacción de topografías de los diferentes lugares del país se percibe como una necesidad científica de importancia, y para facilitar esta tarea las instituciones científicas proporcionan guías o claves adecuadas. Jesús Sánchez MiÑana, Vida y obra del doctor Salvà (1751-1828), Apuntes para la Fundación Española para la Ciencia y la Tecnología (FECYT), 2014, p. 14. https://www.fecyt.es/es/search/node/publicaciones

55 IвÁÑ̃z, Topografía, pág. XXIII.

56 Riera Palmero, Fiebres y paludismo, pág. 31.

57 Iвáñez, Topografía, Discurso Preliminar XVI-XVII. 
En la segunda parte de su Topografía insiste en sus fuentes, enumerándolas ahora de una forma claramente ordenada: autores antiguos, modernos y contemporáneos.

...paso alguno no hemos dados sin el dictamen del incomparable Hipócrates, y demás Príncipes antiguos con lo son Areteo, Alexandro, Traliano, Rhazes, Cornelio Celso, y Celino Aureliano, qual se puede ver citados por el célebre Allier (Aller), discípulo del gran Boerave: y siempre se ha sujetado de mismo modo nuestro pensar a la respetable autoridad de otros tantos sabios modernos que ilustran la noble Ciencia o Arte de sanar. Enumerados entre estos Literatos esclarecidos a Herman Boerave [Boerhaave] ${ }^{58}$, sus tres discípulos Wanswieten, Aller y Degorter; el Sydenham, Offman, Lieutaud, Haen, Morton, Mead, Torti y Baglivio. Y para mejor poder acertar en la práctica de estos tiempos, no hemos dexado de la mano, ni hemos perdido de vista a algunos otros novísimos Escritores, entre ellos al docto Burseiro, que escribió en Padua por el año 1781: el apreciable informe del Real Proto-Medicato, escrito en nombre del Señor Burunda, su Proto-Médico, en el que propone el método para curar Tercianas, año de $1785^{59}$; la Relación que escribió el señor Masdevall ${ }^{60}$, de epidemias, año 1786, y el compendio instructivo, que últimamente publicó el Doctor Don Santiago Puig, año de 1786 y 1787. A exemplar de varones tan circunspectos, como condecorados, he resuelto en la época presente proponer a mis coetáneos y compañeros médicos esta Topografía Hipócrática, que les presento ${ }^{61}$.

Es sumamente interesante comprobar que, cuando se refiere a médicos contemporáneos: Burserius De Kanifeld, Burunda, Masdevall, Morton o Santiago Puig, muchas de las publicaciones por las que son conocidos y apreciados por Félix Ibáñez salen a la luz cuando él ya está enfrascado en el episodio epidémico de la Alcarria. En este sentido, es indudable que utilizo, como se

58 Herman Boerhaave (1668- 1738) médico, botánico y humanista neerlandés.

59 Iвáñez, Topografía, Discurso Preliminar X. En la primera parte de la Topografía opina sobre esta obra de Don José García Burunda La Esquedula Monitoria, [según sus palabras]: «es una cartilla, o mejor decir, es uno de los mejores ejemplares, que se han sujetado a la prensa. Es un Papel breve, claro, estupendo y utilísimo, escrito con erudición, solidez y acierto [...]». Opinión que es recogida al pie de la letra por Joaquín de Villalba Y Guiarte, Epidemiología española, Madrid, Imprenta de Fermín Villalpando, 1803; quien en su página 159 expone: «El Real Tribunal del Protomedicato de Castilla en 21 de septiembre de 1785 publicó en nombre del doctor Don Josef Borunda, un informe, cuyo título es: Schedula monitori "De suerte, dice el doctor Don Félix Ibáñez (I), que sus decretales máximas han sido y serán en lo sucesivo el único tribunal de apelación [...] el conocimiento y cura de las tercianas epidémico-malignas"».

60 Joseph Masdevall, Relación de las Epidemias de calenturas pútridas y malignas que en estos últimos años se han padecido en el Principado de Cataluña, y principalmente la que descubrió el año pasado de 1783, en Lérica, Llano de Urgel, Madrid, Imprenta Real, 1786. [http://hdl.handle.net/10396/7261]

61 IвáñEz, Topografía, págs. 98-99. 
ha apuntado, una de las primeras ediciones italianas de la obra de De Kanifeld, la de Milán 1788 o la de Venecia de 1789, puesto que en 1790 ya la tenía traducida del latín. Por tanto se verifica que ataca a la enfermedad desde todos sus frentes posibles, no solo con la práctica médica, sino también con la observación, la investigación, el recuento y la aplicación de los conocimientos epidemiológicos más vanguardistas de su época. Su constante puesta al día es sin duda encomiable.

Pero si es posible señalar un mentor para Félix Ibáñez, sin duda, este es Hipócrates, conocido a través de la obra Corpus Hippocraticum magna colección de variados textos que han constituido el fundamento de gran parte la medicina desde la Antigüedad hasta el siglo XVIII. Naturalmente nuestro facultativo los conoció de primera mano cómo enuncia el propio título de su obra - Topografía Hipocrática - o sentencias como: «Debemos pues seguir la Medicina Hipocrática, tan recomendable y necesaria, como gloriosa, tan útil como cierta, y en modo alguno sofistica y engañadora». Pero fue a través de la crítica y actualización que realizó del hipocratismo el médico inglés Thomas Sydenham —al que ya se ha hecho referencia-, como interpretó y aplicó esta teoría. E igualmente a través del manifiesto hipocratismo del doctor Piquer y Arrufat ${ }^{62}$ cuya obra conocía profundamente y a quien es posible que hubiera conocido y tratado de manera personal. Por tanto, Félix Ibáñez más que de Hipócrates es seguidor de Sydenham y del doctor Piquer según el cual: «todo conocimiento empieza en la observación y en el análisis racional de los datos obtenidos por la observación; observación de hechos o fenómenos que se ofrece de manera natural y son observables por los sentidos, como por ejemplo los síntomas de las enfermedades; según Piquer los hechos observables al ojo humano 'esto es sinónimo de medicina hipocrática” ${ }^{63}$. Siguiendo estos preceptos Félix Ibáñez introduce en su Topografía, muchas de sus historias clínicas como «Observación» ${ }^{64}$.

Con el mismo sentido audaz y erudito aplica a sus enfermos los tratamientos más novedosos basados en la administración de Quina, pese a la controversia que en esos momentos todavía genera.

No obstante, inmediatamente continúa recalcando lo que para él es más valioso y principal, el haber aplicado las terapias más innovadoras:

${ }^{62}$ Las referencias al doctor Piquer son continuas: IBáñEz, Topografía, Discurso Preliminar VII, págs. $30 ; 38 ; 63$, etc.

63 En Jesús Ángel Espinos, «El Hipocratismo de Andrés Piquer» en Maestre, Barea y Charlo (coords.): Humanismo y pervivencia del mundo clásico: (Homenaje al profesor Antonio Prieto), 2008, págs. 2667-2674.

64 IвÁñ̃z, Topografía, págs. 73-76: «Observación Única. Se ha curado en este Hospital de la Villa de Pastrana [...] Don Alfonso Bernal Sanz [...]», otros ejemplos en pág. 5: «Observación. Tomasa Conde Garcia, edad nueve años $[\ldots]$ », entre otros. 
He pensado no obstante de haber seguido exemplar tan singular, el haber trasladado aquí el modo de practicar y manejar la dignocion y therapeutica de la epidemia de Tercianas, conforme lo han executado en presente y actual época los Doctores Borunda, Burier, Masdevall, Puig, Ortiz, Alsinet, Tisot, Buchan, Cullen y otros; de cuyos célebres Escritores modernísimos hemos formado un formulario en que se han prescrito sus apropiadas recetas para curar la Tercianas [...] las que hemos historiado [... $]^{65}$.

En su obra, el análisis de los posibles tratamientos con Quina recorre sucesivas páginas, desde el apartado titulado «Quina por si sola» donde expone «La Quina sin otro auxilio, por si, es capaz (como en efecto) (así lo hemos experimentado) de curar las Tercianas más tremendas» ${ }^{66}$, hasta la recomendación y explicación de las dos medicinas basadas en la Quina que inventó Joseph Masdevall, la Opiata antifebril y la Mixtura antimonial, que apenas habían sido experimentadas cuando las utiliza Félix Ibáñez, aunque refiriéndose a ellas apunta «una y otra disposición, cumplen toda nuestra idea, como repetidas veces lo tenemos bien experimentado» ${ }^{67}$.

\section{El conde de Cabarrús y Félix Ibáñez}

Pero el uso o no de la Quina no era una cuestión menor ${ }^{68}$. El alcance y la trascendencia de esta epidemia de Tercianas en la Alcarria y en concreto en la población de Pastrana, no solo la conocemos por su médico Félix Ibáñez,

65 IвÁÑEZ, Topografía, Discurso Preliminar XVII.

66 Los diferentes usos que se pueden hacer de la Quina se describen a lo largo de Iвáñ̃z, Topografía, págs. 85-91. Muy posterior es la obra de Thomas de SALazar, Tratado del uso de la quina, Madrid, 1796.

${ }^{67}$ El doctor José Masdevall había inventado estos dos fármacos basados en la Quina y los había parcialmente utilizado en el episodio epidémico que había sufrido Cataluña en 1783. Aunque su uso generó una gran polémica. Félix Ibáñez como vemos siguió sus indicaciones: IBÁñEz, Topografía, pág. 86, y se refiere a él en numerosas ocasiones págs. 112, 114, 140, etc. Sobre la polémica del uso de estas medicinas Juan RIERA PALMERo, José Masdevall y la Medicina española ilustrada. Enseñanza, epidémias y guerra a finales del siglo XVIII, Valladolid, 1980, y Juan Riera PaLmero, Capítulos de Medicina Ilustrada. Libros, cirujanos, epidemias y comercio de la quina, Valladolid, 1992, asegura que Masdevall fue: «artífice del empleo sistemático de la quina».

68 La quina (propiedades antifebífugas), substancia traída del Nuevo Mundo y cuyo comercio tuvo una gran difusión a partir del siglo XVII. En el último cuarto de siglo la quina contó con el respaldo mayoritario de los médicos españoles. Está constatado que fue utilizada en el ejército, en los hospitales regentados por órdenes religiosas, las instituciones benéficas y asistenciales. Sobre el extracción y comercio de la Quina: Riera Palmero, Capítulos de la Medicina.., y Juan Riera Palmero, «El comercio americano de la Quina y las epidemias de paludismo en la España del siglo XvIII", Anales de las II Jornada de Historia de la Medicina Hispanoamericana, Cádiz, (1989), págs. 55-65. Miguel Jaramillo BaAnante (1998), «El comercio de la cascarilla en el norte peruano-sur ecuatoriano: evolución e impacto regional de una economía de exportación, 1750-1796», en S. O'PHELAN y Y. SAINT-GEOURS (eds), «El norte en la historia regional, siglos XVIII- XIX», Lima: Institut Français d'études Andines, p. 51-90 [Consulta: https://books.openedition.org/ifea/3282. 02/11/2018]. 
sino también por la presencia en esta villa de un ilustre viajero en el momento del contagio. Nos referimos al entonces banquero Conde de Cabarrús quien en sus Cartas sobre los obstáculos que la naturaleza, la opinión y las leyes oponen a la felicidad pública (1808), exactamente en su carta V «Sobre la Sanidad Pública» ${ }^{69}$, relata que a finales de los años ochenta había vivido la experiencia de la epidemia en varios pueblos de la Alcarria y cómo el uso de Quina adulterada como medicamento intensificó la mortalidad: «morían hombres a docenas y algunas onzas de quina eran el único auxilio de tres o cuatro pueblos de la Alcarria, entre los cuales distribuí dos arrobas, que apenas bastaron ${ }^{70}$. Esta vivencia fue determinante y cuando fue ministro de Hacienda de José I defendió la institución de un monopolio estatal sobre la producción y venta de la Quina destinada a curar las fiebres, como medio de frenar el lucrativo y amoral comercio de 'quina adulterada'. El ya mencionado médico de Brihuega, Vicente Crespo, expone también este problema, pero de forma más general, al hablar de los boticarios y de la escasa calidad de las medicinas que dispensan ${ }^{71}$.

Indudablemente, el conde de Cabarrús llegó a Pastrana, gracias al literato Leandro Fernández de Moratín, que contaba con lazos familiares en la villa y desde niño viajaba a ella asiduamente ${ }^{72}$. En 1787, Moratín se convierte en secretario personal del conde de Cabarrús, momento de máxima influencia y fortuna del afamado financiero y justo antes de que ambos partan de viaje a Francia. Por razones desconocidas acompaña a Moratín en su viaje a Pastrana donde Cabarrús vive el momento álgido de la epidemia de tercianas. La intensa labor médica de Ibáñez, la presencia de Moratín en Pastrana y la innata curiosidad de Cabarrús hacia los problemas sociales, nos permiten pensar que de la mano de Félix Ibáñez el afamado financiero visitó esos tres o cuatro pueblos de la Alcarria a los que hace mención en su escrito y el médico tuvo ocasión de mostrarle lo pernicioso del problema de la quina adulterada y sus consecuencias, experiencia que le lleva a idear la solución de crear un monopolio estatal para este producto y que expone en su Carta sobre la Sanidad Pública. En realidad, la propuesta de Cabarrús lo que está poniendo de manifiesto es que era posible controlar los brotes epidémicos disponiendo de los medios adecuados, en este caso quina no adulte-

69 Francisco Cabarrús, conde de, «Carta V. Sobre la Sanidad Pública», Cartas sobre los obstáculos que la naturaleza, la opinión y las leyes oponen a la felicidad pública escritas por el conde de Cabarrús al Sr. Don Gaspar de Jovellanos y precedidas de otra al Príncipe de la Paz, Vitoria, Imprenta de Don Pedro Real, 1808, págs. 61-87.

70 Cabarrús, págs. 79-80.

71 Astrain Gallart, «La práctica médica...», pág. 466.

72 Las estancias de Moratín en Pastrana y el importante número de amigos que le visitaba han sido analizados en Esther Alegre Carvajal, "Leandro Fernández de Moratín, su casa de Pastrana y el círculo de sus amigos ilustrados», Cuadernos de Estudios del siglo XVIII, núm. 17, (2007), págs. 41-63. 
rada como medicamento. Reflexión que tal vez fue expresada por Félix Ibáñez. En este sentido, es también muy interesante la reflexión que ofrece Cabarrús en la Carta Primera donde sobre la atención médica al enfermo defiende un cuidado personalizado en su domicilio lo que suponía un sistema médico profesional, tal y como la ejercía la medicina el facultativo de Pastrana:

Qualquiera hombre que tenga un hogar, una familia, un amigo, no necesita hospital, y estará mejor asistido en su domicilio. [...] siempre que los facultativos estén distribuidos con la debida proporción, y que cada pueblo que pueda sufragarlo, [...] tenga médico, cirujano y botica y las aldeas inmediatas puedan acudir y valerse de aquellas proporciones ${ }^{73}$.

\section{La Topografía Hipocrática (1791)}

El texto de la Topografía consta de una Introducción, dos grandes Capítulos y un Apéndice. El primer Capítulo es un estudio general de las fiebres tercianas y el segundo recoge la contribución personal de Félix Ibáñez a las constituciones epidémicas de 1784 y 1791. No es objeto de este artículo analizar las teorías médicas de Félix Ibáñez, sino su figura y el contexto en el que se gesta su obra. Bajo este prisma, ya se ha comentado como la Topografía es un trabajo de investigación que se acomete al tiempo que se propaga la enfermedad epidémica y que se libra la batalla por combatirla desde todos sus frentes posibles: la práctica médica, la observación, la investigación, el recuento, el estudio..., en un encomiable y extraordinario esfuerzo personal por parte del médico responsable.

Félix Ibáñez relata este denuedo con palabras altamente elocuentes: «he ocupado los ratos que me ha sido posible sin defraudar en nada las urgentes obligaciones, en la precisa y diaria asistencia de tanta concurrencia de enfermos como nos ha ocasionado la epidemia de Tercianas... ${ }^{74}$, concurrencia que conocemos por algún dato concreto como: «hoy 14 de Julio [1788], existen de precisa y diaria visita 45 á 50 enfermos». En este sentido Vicente Crespo afirmaba «resultaba moralmente imposible que una vez constituidos en un partido puedan estudiar [los médicos] y leer debido a la multitud de enfermos que tendrán a su cargo ${ }^{75}$, sin necesidad de brotes epidémicos. No obstante a: «que en todo el transcurso de la epidemia han excedió á mis fuerzas, las tareas de mis

73 Cabarrús, Carta Primera, pág. 50.

74 Iвáñez, Topografía, Discurso Preliminar XVI y pág. 157.

75 Astrain GaLlart, «La práctica médica...», pág. 468. 
urgentes ocupaciones» Félix Ibáñez invierte tiempo y esfuerzo en el estudio y el desarrollo del conocimiento:

Y por último, confesamos de buena fe, ha excedido a nuestras fuerzas este incomparable trabajo [el de escribir la Topografía], en un tiempo en que hemos antepuesto la salud de todos a la nuestra. Pero nos podemos gloriar, que se ha trabajo este Papel en el taller de la experiencia, y cabecera de los enfermos, con feliz séquito y acierto.

Antes de la Introducción, siguiendo la costumbre, el texto de la Topografía está precedido de una Dedicatoria: «A quien mejor que a vos circunspecta Villa de Pastrana, puede y debe mi amor, respeto y gratitud, ofrecer el tenuisimo obsequio de esta producción? Cuyo objeto es el bien de la salud pública». Lo que nos revela el hecho concreto de que Félix Ibáñez no tuvo benefactor que financiara su trabajo, y mucho menos la impresión de su obra, y nos permite suponer que fue él mismo el que costeó su edición y, desde luego, que se trató de una iniciativa y una investigación absolutamente personal. Por otra parte, nos ofrece un concepto de 'lo público' estrictamente definido, un bien público como es la salud debe ofrecerse a la comunidad, al público.

A continuación, en la Introducción o Discurso Preliminar, expone como su preocupación por la salud pública es el principal motivo que le ha llevado a redactar el texto. Establece la relación existente entre clima y epidemia, y realiza toda una larga reflexión sobre el Aforismo VIII de Hipócrates. Para dar paso a la Primera parte del Estudio que titula: «Historia del origen, variación, síntomas y manejo curativo de la epidemia de Tercianas», donde hace un recorrido de como se ha ido desarrollando la epidemia y de las causas que la han provocado, determinando que la causa principal es el aire:

En el ayre ha regentado siempre, desde que asestó la epidemia de Tercianas, cierta cualidad secreta y oculta, de superior condición, al conocimiento de su ser [...] hemos llegado a percibir los médicos observantes, que los estragos o desgracias que toleraban los míseros tercianos procedían, no de otro ente o agente más principal, que una porción etherea, ígnea, sulfúrea y volátil, que ha andado enredada en el ayre ${ }^{76}$.

A continuación entra en el cuerpo del libro, con una larga disertación en la que expone las diferentes teorías sobre las Tercianas según un amplísimo

${ }^{76} \quad$ Iвáñ̃z, Topografía, pág. 14. 
abanico de autores, revelando su agudo juicio crítico, que da paso al objetivo principal del primer Capítulo, realizar una estricta clasificación de las tercianas y de sus tratamientos, siguiendo un criterio clínico, lo que le permite referenciar otras muchas enfermedades que se manifiestan a la vez, como «El Sarampion que acompaña a estas fiebres...» ${ }^{77}$. Los tratamientos se explican con un alto grado de detalle, contrastando su opinión con la literatura médica y con referencias constantes al resultado obtenido en casos y enfermos concretos.

La segunda parte del estudio que denomina Apéndice ${ }^{78}$, de forma cronológica analiza las condiciones climáticas de cada mes empezando por noviembre de 1784 y luego da paso a los sucesos Médico-prácticos que elige ${ }^{79}$. Muy interesante y detallada es la narración de la enfermedad de su esposa «Suceso desde 7 de marzo hasta el día 15», donde incluye la intervención de sus colegas médicos cercanos $^{80}$, así como su propia enfermedad ${ }^{81}$. De forma más rápida hace referencia a la enfermedad de su hija Ramona que curó, aunque se convierte en el caso que sirve como ejemplo y contraste para analizar otros episodios de la enfermedad $^{82}$. No solo introduce casos individuales, sino que también da noticias de forma más general como: «Suceso V. En el noviciado del Convento de San Pedro de Pastrana de Carmelitas Descalzos» donde atendió a más de 30 novicios ${ }^{83}$.

\section{La Epidemia de Tercianas: El desarrollo de la enfermedad}

El siglo XVIII se convirtió en la centuria, por excelencia, de las fiebres en la historia médica de España ${ }^{84}$; durante la primera mitad no hubo grandes emer-

77 IвÁñEz, Topografía, pág. 32.

78 IвÁÑEz, Topografía, pág. 98, lo titula «Sobre ciertos y determinados sucesos Médico prácticos, que se han observado en las anuales y diversas constituciones de la epidemia de Tercianas, desde el año de 1784, hasta el de 1790 y 91 »

79 Observaciones muy interesantes para la historia del clima.

80 IвÁÑEZ, Topografía, Pág. 173-179. «Gabriel Ortega, Titular cirujano de esta Villa, mi compañero y amigo».

${ }^{81}$ IвÁÑEz, Topografía, págs. 166-169. «Como estuve enfermo desde primero de Noviembre, hasta últimos de Diciembre», para en la historia precisar «salí á visitar el dia quince de Diciembre», que nos permite conocer, como en el caso de su esposa, la atención recibida por parte de los médicos de toda la comarca: «Y los Médicos que me asistían, en vista de la postración de fuerzas que en mi advertian, y algun desorden en mis operaciones mentales, juzgaron en el dia seis era ya mi última hora llegada, me desampararon en algun modo, y se retiraron á sus partidos, y previnieron sigilosamente se me administrase la Santa Extrema-Uncion, que no tuvo efecto por haberme venido un sudor calido, universal y crítico en el dia séptimo que me quitó la calentura, y quedé del todo bueno».

82 Іви́̃̃Ez, Topografía, pág. 183 y pág. 188.

83 Iвáñ̃z, Topografía, pág. 118.

84 Bertrán Moya, Historia de las epidemias, pág. 104. 
gencias de mortalidad catastrófica, puesto que la peste, la gran plaga de siglos anteriores no volvió a aparecer, lo que permitió un crecimiento sostenido de la población ${ }^{85}$; sin embargo, la mortalidad epidémica lejos de desaparecer, se agravó bruscamente a finales de siglo y durante los primeros años del siglo XIX, causando una preocupación constante para los gobernantes ilustrados de los reinados de Carlos III y Carlos IV, por la alta mortalidad de las enfermedades febriles. Lo que también nos ha dejado algunos de los mejores ejemplos de la literatura y del compromiso médico al servició del bienestar público ${ }^{86}$, como es el caso de Félix Ibáñez.

En este sentido, a partir de $1783^{87}$ se inicia la epidemia de Tercianas que nos ocupa la más grave e intensa de todo el siglo, puesto que vino acompañada de viruela o de tifus. Desde la zona de levante se propagó al resto de la península y sus momentos más álgidos se vivieron entre 1784 y 1786, aunque su actuación se prolongó durante más de una década ${ }^{88}$.

Según Félix Ibáñez en la Alcarria: «Amenazó la epidemia de Tercianas en Septiembre de 1783, siguió el año de 1784, continuó y prevaleció en los años de $1785,1786,1787$, y sus depravadas resultas, se experimentaron por los años de 1788, 1789, hasta 1790 y 91 que cesó», aunque a continuación precisa: «Luego pues que se acabó la epidemia de Viruelas, que se padeció no solamente en toda la provincia de la Alcarria, sino en esta Villa de Pastrana y sus inmediaciones; por el año 1784 comenzó la epidemia de Tercianas» ${ }^{89}$. Es decir, en 1784 es cuando empieza la epidemia de Tercianas pero fue especialmente virulenta en 1785 y 1786. Las causas fueron variadas, Ibáñez señala entre ellas la sequía, pero sobre todo el movimiento tropas españolas y francesas que entiende son las posibles portadoras de la epidemia.

Pastrana contaba hacia 1784, con unos 800 o 900 vecinos, una población aproximada de 3.000 personas $^{90}$. Ese año se padeció la enfermedad de viruelas, que afectaron a unas 1200 personas y acabó con la vida de 95 o 100 niños. El cuadro era igualmente catastrófico en poblaciones próximas. En 1785, en Escopete entre agosto y septiembre murieron 76 personas: «Muchachos de 10 a 15 años no se libraba uno, todos morían». En 1786 la epidemia de Tercianas estaba en ascenso, coincidiendo con la grave difusión del contagio en toda España, y descendió y parecía extinguida a comienzos de 1787. Sin embargo, esto no fue

\footnotetext{
85 Bertrán Moya, Historia de las epidemias, pág.103.

86 Bertrán Moya, Historia de las epidemias, pág. 105.

87 Joseph Masdevall en1783 fue nombrado Inspector General de Epidemias.

88 Bertrán Moya, Historia de las epidemias, pág. 112.

89 IвÁÑEZ, Topografía, pág. 1.

90 Iвáñez, Topografía, pág. 12.
} 
así: «en esta inteligencia habíamos proyectado en este clima, se había extinguido ya todo genero de contagio epidémico; pero parece no es así, [...]De aquí infiero, y por propia experiencia repito, que apenas acaba una epidemia cuando ya tenemos otra encima» ${ }^{91}$.

Se puede calcular que Félix Ibáñez visitó a unos 4000 enfermos de los cuales murieron unos 700, algo más del 15\%:

[...] en este recinto de Pastrana [...] llega el número de fallecimiento al número de trescientos en tiempo regular; pero en el tiempo irregular como ha sido el de la epidemia, se ha duplicado y se colige que asciende el total de fallecidos de seiscientos a setecientos ${ }^{92}$.

Pero como el mismo explica:

$[\ldots]$ no indultó la tiranía de la epidemia calidad de persona alguna [...]. Acometieron a los nobles y plebeyos, a ricos y pobres a grandes y chicos, a fuertes y endebles [...] y para decirlo de una vez, fue comprenhendiendo en esta plaga todo viviente nacional que le precisa estar rodeado del fluido aéreo contagiable y epidémico, de que ha habido muy pocos que se han escapado, o por mejor decir, nadie ha estado libre del maligno contacto que ha viciado el ayre y demás mantenimientos que sustentan al hombre... ${ }^{93}$.

La intensa práctica profesional de Félix Ibáñez dejó una honda huella en Pastrana. Directamente a su influencia se deben numerosísimas mejoras que se van a realizar en viviendas particulares con la apertura de ventanas para una mayor ventilación o en los conventos de las cuatro comunidades religiosas de Pastrana para reforzar su salubridad ${ }^{94}$. Desde luego se convirtió en el cauce para impulsar en la población de Pastrana una fuerte conciencia sobre las nociones de salubridad, sobre la amenaza de los aires corruptos, de los miasmas, sobre

91 Iвáñ̃z, Topografía, pág. 190, pone: Nota remarca esta idea: «Es de admirar por cierto que al tiempo que dio principio la epidémia de Tercianas [...] cesase la epidémia de viruelas del año de mil setecientos ochenta y cuatro, y luego que termina la de Tercianas, ya tenemos otra nueva epidemia variolosa».

92 IвáñEz, Topografía, pág. 14.

93 IвÁÑEZ, Topografía, pág. 13 y 34.

94 Las cuatro comunidades religiosas fueron: frailes Franciscanos, frailes carmelitas descalzos, monjas concepcionistas franciscanas y cabildo de la iglesia Colegial. Todos sus miembros fueron atendidos durante la epidemia por Félix Ibáñez, y en sus respectivos conventos fueron realizadas importantes reformas con el propósito de mejorar la salubridad de las instituciones. Esther Alegre Carvajal, «Un convento, un lugar, múltiples historias», en La colección artística del Convento de Carmelitas Descalzos de San Pedro de Pastrana. Catálogo del Museo del V Centenario de Santa Teresa de Jesús, Guadalajara, 2018. 
el beneficio de la ventilación y el peligro de las aguas estancadas, creando una nueva sensibilidad, que se concreta en un rechazo y una intolerancia a los «malos olores» ahora perfectamente identificados con la enfermedad ${ }^{95}$.

95 Estas cuestiones las hemos estudiado en: Esther Alegre Carvajal, «El control municipal y los procesos de privatización en el siglo XIX. El caso de Pastrana», e-Legal History Review, vol. 11, 2011, pp. 1-43. Esther Alegre Carvajal, «Una imagen transformada: Pastrana durante el siglo Xix. Venta de soportales y terrenos de la vía pública», Wad-Al-Hayara, vol. 35-36-37, 2011, pp. 357-384. Alegre CARvajal, «El discurso médico-higienista ilustrado..., págs. 250-263. 